\title{
Ana Heva lava tube (Easter Island, Chile): Preliminary characterization of the internal layers of coralloid-type speleothems
}

Miller, A.Z. , Pereira, M.F.C* , Calaforra, J.M. ${ }^{* *}$, Forti, P. ${ }^{* * *}$, Dionísio, A. ${ }^{*}$ and Saiz-Jimenez, C. ${ }^{* * * *}$

* CERENA/CEPGIST, Instituto Superior Técnico, Universidade de Lisboa, Av. Rovisco Pais, 1049-001, Lisbon, PORTUGAL

${ }^{* *}$ Department of Biology and Geology, University of Almeria, Ctra. Sacramento s/n, La Cañada de San Urbano 04120, Almería, SPAIN

${ }^{* * *}$ Department of Earth Sciences and Environmental Geology, University of Bologna, Via Zamboni 33, 40126, Bologna, ITALY

${ }^{* * * *}$ Instituto de Recursos Naturales y Agrobiologia, IRNAS-CSIC, Av. Reina Mercedes 10, 41012, Seville, SPAIN

Email: ana.miller@tecnico.ulisboa.pt

Coralloid-type speleothems were found in Ana Heva lava tube from Easter Island (Chile). The ceiling of the lava tube presents light to dark brown speleothems with globular coral-like shape. To appraise their internal structure and composition, optical microscopy (OM) of cross-sections, field emission scanning electron microscopy with energy dispersive X-ray spectroscopy (FESEM-EDS) and X-Ray micro-computed tomography $(\mu \mathrm{CT})$ were performed. The latter is a non-destructive method (NDM), performed to assess physical and compositional heterogeneities of the coralloids.

The internal structure of these speleothems comprises a succession of thin layers, ranging from white to brown, with vitreous to resinous luster (Fig. 1A). According to their color and texture, four major layers are easily distinguishable, from the surface to their inner part: a superficial dark brown to black coating, with approximately $0.1 \mathrm{~mm}$ thick (L1); a $0.1-1 \mathrm{~mm}$ thick semi-transparent grayish layer (L2); a 0.1-1 mm thick white layer (L3), and a heterogeneous honey brown layer, with 1-5 mm thick and shades ranging from yellowish to honey brown (L4). FESEM-EDS microanalyses performed on the internal layers of longitudinally cut coralloid samples (Fig. 1B) showed systematic differences in chemical composition of the different color inner layers. In general, they contain variable proportions of $\mathrm{Si}, \mathrm{Mg}$ and $\mathrm{Ca}$ (Fig. $1 \mathrm{C}-\mathrm{G}$ ).

According to a previous study [1], the thin dark brown to black coating of the coralloid surfaces is probably derived from the weathering of the overlying volcanic rock and microbial activity [1]. The semi-transparent grayish layer (L2) is composed of low crystalline silica (opal-A), whereas the whitish layers (L3) are calcium carbonate (calcite). In contrast, the honey-brown layers (L4) present an unusual composition characterized by high levels of $\mathrm{Mg}$, corresponding to an amorphous $\mathrm{Mg}$ hydrate silicate. Significant content of organic carbon was also found in these layers [1].

The $\mu \mathrm{CT}$ study allowed us to confirm the existence of internal zoning in the studied coralloids (Fig. 2), and between them and the basaltic substrate. The brighter domains in the reconstructed images (Fig. 2D,E) correspond to the vacuolar basaltic. The other opaque domains, comprising thin spheroidal precipitates or dispersed spots within the coralloids (Fig. 2F-I), are calcium rich phases. According to mineralogical data and FESEM-EDS analysis, the inner/older spots correspond to apatite and the outer/more recent spots correspond to calcite. In contrast, the $\mathrm{Si}, \mathrm{Mg}$ and $\mathrm{C}$ enriched domains are more transparent to X-ray radiation, combining at least two main phases (siliceous and magnesium silicate compounds). The proposed methodology was considered adequate for studying coralloid samples, by combining a NDM $(\mu \mathrm{CT})$ with other microanalytical techniques. Investigations of speleothems using the potentialities of $\mu \mathrm{CT}$ provide general morphological and compositional information, suggesting the best approach for selecting and 
sectioning the samples. The FESEM-EDS provides characteristic information on the morphological, mineral and chemical composition.

The authors acknowledge FCT for PEst-OE/CTE/UI0098/2011, AZM (SFRH/BPD/63836/2009) grant, and Spanish Ministry of Science and Innovation (Project CGL2011-2569) and CSIC 210230E125.

[1] Miller, A.Z. et al., Geomicrobiology Journal, 31, 1-10, 2014.

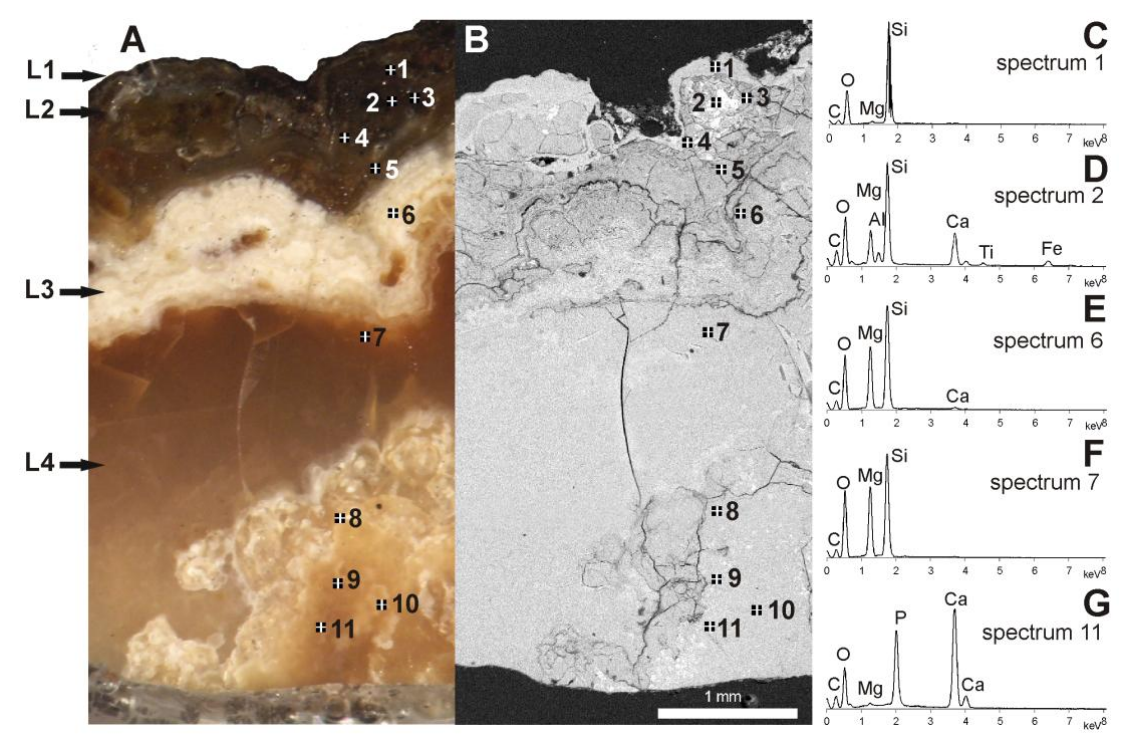

Figure 1. A. Longitudinal section of an individual coralloid speleothem from Ana Heva lava tube showing different colored layers (L1, L2, L3 and L4). B. Composed FESEM image of the coralloid longitudinal section. C-G. EDS microanalyses obtained in positions 1 to 11.

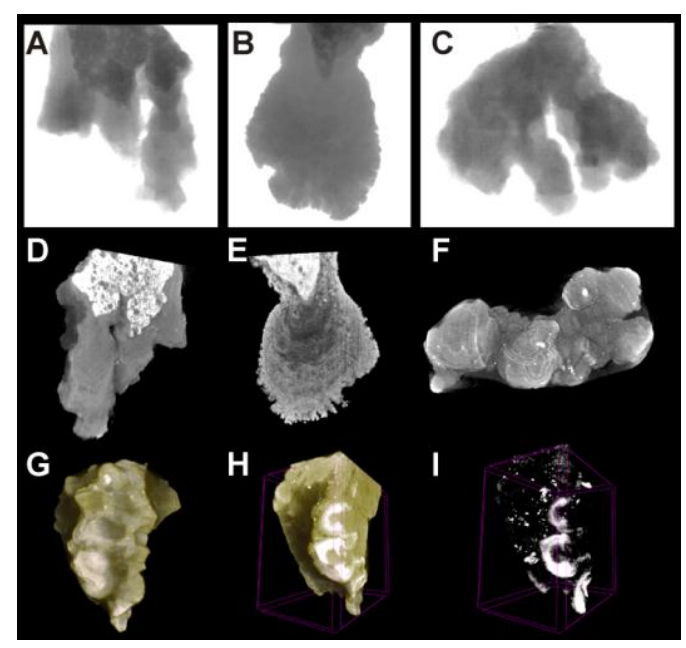

Figure 2. Coralloid radiographs (A-C) and $3 \mathrm{D}$ views based in reconstructed $\mu \mathrm{CT}$ images (D-I); Bulk $(\mathrm{D}, \mathrm{G})$, sectioned $(\mathrm{E}, \mathrm{H})$ and transparent $(\mathrm{F}, \mathrm{I})$ mode views, showing heterogeneous composition and the existence of internal zoning. 